Vol.: 5 Issue: 2 Date: 31.12.2021 Received: 28.08.2021 Accepted: 29.09.2021 Final Version: 31.12.2021

ISVOS Journal, 2021, 5(2): 107-114 - https://doi.org/10.47897/bilmes.988009

\title{
Matrix Pencil Method and Singular Value Decomposition Application for DOA Estimation Using Linear Antenna Array with Multiple Signal Sources
}

\author{
Nilay Aytaşa,, Erkan Afacan $^{\mathrm{b}}$, Nihat İnanç

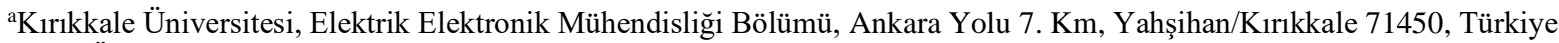

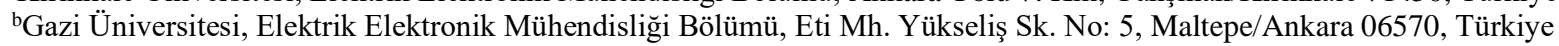 \\ ORCID ID: 0000-0002-8305-1641 \\ ORCID ID: 0000-0003-4025-6847 \\ ORCID ID: 0000-0003-2989-6632
}

\begin{abstract}
The practice of estimating the direction of the signal emitted from signal sources using linear antenna arrays is used effectively in both military and civilian radar systems. While the number of signal sources was single in the first studies, the systems that estimated the direction angle of the source have now gained the ability to estimate the direction angle of the signals emitted from more than one signal source at the same time with high accuracy, thanks to the deepening researches. In this study, it is aimed to estimate the angle of incidence of noisy signals emitted from multiple signal sources with the least error by using the Matrix Pencil Method and linear antenna array, which is one of the signal subspace analysis methods. In addition, the signals are separated from the noise factor by using the Singular Value Decomposition method. Simulations have been carried out in many different scenarios, and it has been shown that the combination of Matrix Pencil Method and Singular Value Decomposition methods can be used for highly accurate results in estimating the direction of multiple signals coming into the antenna array.
\end{abstract}

Keywords: "matrix pencil, singular value decomposition, array signal processing, doa estimation, linear antenna array."

\section{Giriş}

Sinyal geliş açısı tahmini üzerine yapılan çalışmalar, araştırmacılar tarafından uzun yıllardır önemli bir uğraş alanı olmuştur. Tek ya da birden fazla sinyal kaynağından yayılan sinyallerin yönünün açısı, belirli geometriye sahip anten dizileri kullanılarak sinyal işleme teknikleri ile tahmin edilebilir olduğu çalışmalar sonucunda ortaya çıkmıştır. Birçok pratik sinyal işleme probleminde amaç, temel gerçek sinyallerin bağlı olduğu bir dizi sabit parametreyi ölçümlerden tahmin etmektir. Örneğin, bir anten dizisinde alınan sinyaller kümesi göz önüne alındığında, diziye çarpan sinyallerin geliş yönlerinin tahmin edilmesi, radar, sonar, elektronik gözetleme ve sismik keşif gibi oldukça alanlarda önemlidir. Yüksek çözünürlüklü frekans tahmini, Doppler radarı ve sistem tanımlama dahil olmak üzere çok sayıda uygulamada kullanılır. Tahmin edilecek parametreler, gözlemlere bağlı parametrelerdir. Örnek verecek olursak, düzlem dalgaların geliş yönü tahminini sağlamak için yeterli veri toplamak gerekir ve istenen doğruluk ancak yeterince uzun olan gözlem aralığı sabit iken elde edilebilir [1].

Literatürde dizi verisi işlenmesi, sinyal kaynaklarına ait parametrelerin dizi antenler kullanılarak elde edilmesi olarak adlandırılır. Bu durum, ışıma kavramına uygun olarak iletilen sinyallerin işlenmesi ile ilgilidir. Serbest uzayda yerleştirilmiş halde bulunan sinyal kaynaklarının dizi antenler üzerine 1şıma yapması sonucu elde edilen sinyallerle ilgili bütün parametrelerin kestirilmesi asıl amaç olarak görülmektedir. Bu parametreler arasında başlıcaları; kaynak sayısı, kaynakların yatay ve yükseliş açıları, konumları ve frekansları olarak sayılabilir [2].

Sinyal geliş açısı tahmin problemlerinde, Capon'un maksimum olabilirlik (Maximum Likelihood) yöntemi [3] ve Burg'un maksimum entropi (Maximum Entropy) yöntemi [4] dahil olmak üzere çeşitli yaklaşımlar olmuştur. Genellikle başarılı olmalarına ve yaygın olarak kullanılmalarına rağmen, bu yöntemlerin belirli temel sınırlamaları vardır. Bunlar, parametre tahminlerinde yanlılık ve hassasiyettir. Çünkü büyük ölçüde ölçümlerin yanlış bir modelini (örneğin, özel ARMA yerine AR) kullanırlar. Pisarenko, bir kovaryans matris yaklaşımı kullanarak toplamsal gürültüde parametrelerin tahminini yaparak, veri modelinin yapısından yararlanan ilk araştırmacılardan biridir [5]. Schmidt [6] ve ayrı olarak Bienvenu ve Kopp [7], keyfi formdaki anten dizilerini kullanarak yön bulan ilk araştırmacılardır. Özellikle Schmidt, bunu önce gürültünün yokluğunda tam bir geometrik çözüm türeterek, ardından gürültünün varlığında makul bir yaklaşık çözüm elde etmek için geometrik kavramları akıllıca genişleterek başarmıştır. Ortaya çıkan algoritma MUSIC (çoklu sinyal sınıflandırması) olarak adlandırılmış ve bu algoritma geniş çapta incelenmiştir. MUSIC algoritmasının üzerine kurulduğu geometrik kavramlar, çok daha geniş bir alt uzay tabanlı algoritmalar sınıfının temelini oluşturur. Schmidt'in öncü çalışmasından bu yana, alt uzay yaklaşımına dayalı birkaç teknik geliştirilmiştir.

${ }^{1}$ Sorumlu Yazar. Tel: +905456384883

E-posta adresi: aytasnilay@gmail.com 
Özellikle, Paulraj, Roy ve Kailath [8, 9, 10] tarafından önerilen ESPRIT tekniği (dönel değişmezlik teknikleri aracılığıyla sinyal parametrelerinin tahmini) bu yöntemlerden biridir. Nispeten daha yakın zamanlarda, Ottersten ve Kailath'ın [11] klasik maksimum olabilirlik yöntemi ve ağırlıklı alt uzay uydurma gibi çok boyutlu tekniklerdeki sonuçlar, potansiyel olarak üstün performanslarından dolayı dikkat çekmiştir. Hata çeşitlemesinde Cramer-Rao alt sınırını elde eden tahminler yapmak için optimal bir ağırlıklandırma seçimi gösterilmiştir [12].

1986 yılında, yön bulma çalışmaları hız kazanmış ve Sibul, uyarlanabilir bir anten dizisi kullanarak yapılan 1şımada, Tekil Değer Ayrışımı anten sayısının kaynak sayısından fazla olması problemini çözmek için kullanılmıştır [13]. Hua ve Sarkar, 1990 yılında, Tekil Değer Ayrışımı yöntemi ile Matris Kalem yöntemini gürültülü bir sinyale ait genelleştirilmiş özdeğerleri bulmak için kullanmıştır [14]. Sarkar ve Pereira, 1995 yılında, Matris Kalem yöntemini bir sinüs sinyaline ait karmaşık üstel fonksiyonların toplamını tahmin etmek için uygulamış ve ayrıntılarıyla incelemiştir [15]. Yılmazer, Sarkar ve Salazar-Palma, sinyalden aldıkları tek örnek ve çoklu örnekle sinyalin geliş açısı tespitini ESPRIT yöntemi ile Matris Kalem yöntemini birlikte kullanarak 2010 yılında yapmışlardır [16]. Parametre tahmini [17]'de yapılmış, [18]'de, doğrusal ve çembersel anten dizisine iki boyutlu Matris Kalem yöntemi uygulanmıştır. [19]'da Matris Kalem yöntemi ile iki sinyal kaynağı kullanılmış ve sonuçlar sunulmuştur.

Bu çalışmada, Matris Kalem yöntemi ve Tekil Değer Ayrışımı yöntemi kullanılarak doğrusal bir anten dizisine ışıma yapan sinyallerin geliş açısı tahmini yapılmıştır. Çoklu sinyal kaynakları kullanılmış olup farklı senaryolar için simülasyonlar sunulmuştur. Diğer çalışmalardan farklı olarak aynı anda ışıma yapan kaynak sayısı birden fazla olması durumu incelenmiştir. Önerilen yöntemin, geliş açısı tahmini üzerine etkisini incelemek için sinyal kaynaklarının açıları ve gürültü seviyeleri değiştirilmiştir. Ayrıca anten elemanı sayısının değişimi de analiz edilerek doğrusal anten dizisindeki etkisi elde edilen sonuçlar ile birlikte sunulmuştur. Birbirinden farklı geliş açılarına sahip gürültülü sinyallerin geliş yönleri, Matris Kalem ve Tekil Değer Ayrışımı yöntemleri ile tahmin edilip, elde edilen sonuçların RMSE değerleri karşılaştırmalı olarak gösterilmiştir.

\section{Matris Kalem ve Tekil Değer Ayrışımı Yöntemlerinin Sinyal Veri Modeline Uygulanması}

Matris Kalem yöntemi yüksek hassasiyetle kutup ve genlik verilerinin üstel sinyal verilerinden elde edilmesini sağlar. Bu yöntem de diğer kestirim yöntemleri gibi alt uzay yaklaşımı tabanlı bir yöntemdir. Matris Kalem yöntemini diğer MLE, MUSIC ve ESPRIT yöntemlerinden ayıran en önemli fark tüm bu yöntemler, R korelasyon matrisine bağımlı olarak görev yaparken Matris Kalem yönteminin korelasyon matrisine ihtiyaç duymamasıdır. Korelasyon matrisini tahmin etmek önemli bir hesaplama yüküdür, çünkü $\mathrm{N}$ anten elemanı sayısı olmak üzere, $\mathrm{K}>2 \mathrm{~N}$ olan veri sinyalinin en az K (anlık görüntüler) örneğine ihtiyaç vardır. Doğal varsayım, tüm K örneklerinin aynı istatistikleri takip etmeleri, yani verilerin homojen olmasıdır. Bu, Matris Kalem olarak bilinen “istatistiksel olmayan” veya “doğrudan veri alanı” tekniğinin geliştirilmesini motive etmiştir. [14]. Matris Kalem yöntemi, aslen bir sistemin kutupların tahmini için geliştirilmiştir ancak aynı zamanda sinyal geliş açısı tahminine de uygulanabilir. Orijinal Matris Kalem yönteminde zaman indeksi olan $\mathrm{n}$ için alınan veriler aşağıdaki şekilde verilir.

$$
\begin{gathered}
x_{n}=\sum_{m=1}^{M} A_{m} z_{m}^{n}+n_{n} \\
z_{m}=e^{j k d \sin (\theta)}, \quad m=1,2, \cdots, M
\end{gathered}
$$

Burada gürültü içeren sinyallere Matris Kalem yönteminin uygulanması için öncelikle $x_{n}$ vektörünün, düzgün doğrusal anten dizisinde anten elemanlarının besleme noktasında ölçülen gerilim kümesi olduğu varsayılır. M adet sinyal kaynağının olduğu varsayılmıştır. $A_{m}$ uyarım katsayısını, $z_{m}$ sistemin kutuplarını ve $n_{n}$ ortalama beyaz Gauss gürültüsünü ifade eder. Eşitlik 2'de, $k$ değeri dalga numarasını, $d$ değeri antenler arası mesafeyi, $\theta$ ise kaynaktan gelen sinyalin açısını gösterir.

Yöntemin uygulanmasında amaç, verilen $x_{n}$ sinyalinden $z_{m}$ değerlerini tahmin etmektedir $(n=0,1, \cdots, N-1)$. Bu problemde, veriler $\mathrm{N}$ adet anten elemanlarının terminallerinde alınır ve aynı teoriksel şekilde anten dizisine uygulanır. Böylelikle, orijinal Matris Kalem algoritması sinyal geliş açısı tahmini için de geçerli olmuş olur. Matris Kalem yöntemi, bir korelasyon matrisi tahmin etmeden ESPRIT tekniğiyle birçok benzerlik içerir. Yöntemi uygulamak için orijinal veri vektöründen elde edilmiş iki tane matris tanımlanır.

$$
\boldsymbol{X}_{0}=\left[\begin{array}{cccc}
x_{0} & x_{1} & \cdots & x_{L-1} \\
x_{1} & x_{2} & \cdots & x_{L} \\
\vdots & \vdots & \ddots & \vdots \\
x_{N-L-1} & x_{N-L} & \cdots & x_{N-2}
\end{array}\right]_{(N-L) \times L}
$$




$$
\boldsymbol{X}_{1}=\left[\begin{array}{cccc}
x_{1} & x_{2} & \cdots & x_{L} \\
x_{2} & x_{3} & \cdots & x_{L+1} \\
\vdots & \vdots & \ddots & \vdots \\
x_{N-L} & x_{N-L+1} & \cdots & x_{N-1}
\end{array}\right]_{(N-L) \times L}
$$

Eşitlik 3 ve Eşitlik 4'te verilen L, kalem parametresi olarak adlandırılır. L değeri, algoritmanın en iyi sonucu verebilmesi için $N / 2$ ile $N / 3$ arasında seçilmelidir. Ayrıca aşağıda kalem parametresinin sağlaması gereken diğer şartlar da verilmiştir.

$$
\begin{aligned}
& M \leq L \leq N-L, \quad N \text { değeri çift ise } \\
& M \leq L \leq N-L+1, \quad N \text { değeri tek ise }
\end{aligned}
$$

Matris Kalem yöntemini, teorinin temelini esas alarak aşağıdaki eşitlikleri yazabiliriz.

$$
\begin{gathered}
X_{0}=Z_{1} A Z_{2} \\
X_{1}=Z_{1} A \psi Z_{2}
\end{gathered}
$$

Burada $\boldsymbol{\psi}$, tahmin etmek istediğimiz diyagonal matristir. Tanımlanan matrisler aşağıda verilmiştir.

$$
\begin{aligned}
& \boldsymbol{Z}_{1}=\left[\begin{array}{cccc}
1 & 1 & \cdots & 1 \\
Z_{1} & z_{2} & \cdots & z_{M} \\
\vdots & \vdots & \ddots & \vdots \\
z_{1}^{(N-L-1)} & z_{2}^{(N-L-1)} & \cdots & z_{M}^{(N-L-1)}
\end{array}\right]_{(N-L) \times M} \\
& \boldsymbol{Z}_{2}=\left[\begin{array}{cccc}
1 & z_{1} & \cdots & z_{1}^{(L-1)} \\
1 & z_{2} & \cdots & z_{2}^{(L-1)} \\
\vdots & \vdots & \ddots & \vdots \\
1 & z_{M} & \cdots & z_{M}^{(L-1)}
\end{array}\right]_{M \times L} \\
& \boldsymbol{\psi}=\left[\begin{array}{cccc}
z_{1} & 0 & \cdots & 0 \\
0 & z_{2} & \cdots & 0 \\
\vdots & \vdots & \ddots & \vdots \\
0 & 0 & \cdots & z_{M}
\end{array}\right]_{M \times M} \\
& \boldsymbol{A}=\left[\begin{array}{cccc}
\alpha_{1} & 0 & \cdots & 0 \\
0 & \alpha_{2} & \cdots & 0 \\
\vdots & \vdots & \ddots & \vdots \\
0 & 0 & \cdots & \alpha_{M}
\end{array}\right]_{M \times M}
\end{aligned}
$$

Burada, $\boldsymbol{X}_{0}$ ve $\boldsymbol{X}_{1}$ matrislerinin rankı M'dir. Eşitlik 13'de Matris Kalem yönteminin bu matrislere uygulanmış hali verilmiştir.

$$
X_{1}-\lambda X_{0}=Z_{1} A[\psi-\lambda \mathbf{I}] Z_{2}
$$

$\left[\boldsymbol{X}_{0}, \boldsymbol{X}_{1}\right]$ matris çiftinin genelleştirilmiş özdeğerlerini bulmak için sistemin kutupları olan $z_{M}$ değerlerinin bulunması gerekir.

$$
\boldsymbol{X}_{1} \boldsymbol{q}-\lambda \boldsymbol{X}_{0} \boldsymbol{q}=0
$$

Eşitlik 14'de, genelleştirilmiş özvektör olan q'nun korelasyon matrisinin özvektörleriyle hiçbir ilişkisi olmadığ 1 unutulmamalıdır. $\mathrm{Bu}$ matris çiftinin $\mathrm{M}$ adet olan genelleştirilmiş özdeğerleri, $z_{m}$ değerlerinin tahminlerini oluşturur. Böylelikle sinyal geliş açısı tahmini Eşitlik 15 kullanılarak elde edilebilir.

$$
\theta=\cos ^{-1}\left[\frac{\operatorname{Im}\left(\ln \left(z_{m}\right)\right)}{k d}\right], m=1,2, \ldots, M
$$


Matris Kalem yöntemi, sinyalin gürültü içermesi durumunda gürültü alt uzayını ayırt edemez. Bu nedenle doğrusal anten dizisine gelen sinyalin gürültü içermesi halinde ilk olarak Tekil Değer Ayrışımı yönteminin uygulanması gerekmektedir. Tekil Değer Ayrışımı yöntemi, gürültü içeren sinyallerde, gürültüyü sinyal alt uzayından ayırt etme işlemini gerçekleştirir. Böylece, gürültüden arınmış olan sinyal, Matris Kalem algoritması ile işlenebilir. $\boldsymbol{X}$ matrisine Tekil Değer Ayrışımı yöntemi uygulandığında Eşitlik 16 elde edilir.

$$
[\boldsymbol{X}]=[\boldsymbol{U}][\boldsymbol{S}][\boldsymbol{V}]^{H}
$$

Verilen denklemde $[U]$ ve $[V]$ üniter matristir, $[S]$ matrisi köşegen matristir ve $[X]$ 'nin tekil değerlerini içermektedir. Kaynaktan gelen sinyallere bahsedilen işlemler uygulandıktan sonra filtrelenmiş matris oluşturma işlemi yapılır. Burada matris $\left[V^{\prime}\right]$ ile gösteriliir ve $[V]$ matrisinin $M$ adet baskın sağ tekil vektörlerinden oluşmaktadır.

$$
\left[V^{\prime}\right]=\left[v_{1}, v_{2}, \ldots ., v_{M}\right]
$$

Diğer tekil değerlere oranla, $M+1$ 'den $L$ değerine kadar olan sağ tekil vektörler oldukça küçük değerlerdedir ve atılması gerekir. Öyleyse,

$$
\begin{aligned}
& {\left[\boldsymbol{X}_{0}\right]=[\boldsymbol{U}]\left[\boldsymbol{S}^{\prime}\right]\left[\boldsymbol{V}_{1}^{\prime}\right]^{H}} \\
& {\left[\boldsymbol{X}_{1}\right]=[\boldsymbol{U}]\left[\boldsymbol{S}^{\prime}\right]\left[\boldsymbol{V}_{2}^{\prime}\right]^{H}}
\end{aligned}
$$

elde edilir. Burada, $\left[V^{\prime}\right]$ matrisinin son sırası silindiğinde $\left[V_{1}^{\prime}\right]$ matrisi oluşturulur. $\left[V^{\prime}\right]$ matrisinin ilk sirası silindiğinde $\left[V_{2}^{\prime}\right]$ matrisi oluşturulur. [S] matrisinin baskın tekil değerlerinin olduğu $M$ sütundan ise [ $\left.S^{\prime}\right]$ matrisi meydana gelir. Öyleyse, Eşitlik 20 'nin özdeğerleri, gürültü içeren sinyallerin geliş açısını tahmin etmek için kullanılması gereken eşitliktir.

$$
\left\{\left[\boldsymbol{V}_{2}^{\prime}\right]^{H}-\lambda\left[\boldsymbol{V}_{1}^{\prime}\right]^{H}\right\} \rightarrow\left\{\left[\boldsymbol{V}_{1}^{\prime}\right]^{H}\right\}^{+}\left\{\left[\boldsymbol{V}_{2}^{\prime}\right]^{H}\right\}^{+}-\lambda[\boldsymbol{I}]
$$

Buradan elde edilen özdeğerler ile Eşitlik 15 kullanılarak gürültülü sinyallerde işaret geliş açısı kestirimi yapılır. Matris Kalem yöntemini herhangi bir sinyale uygulama adımları Tablo 1'de özetlenmiştir.

Tablo 1. Matris Kalem ve Tekil Değer Ayrışımı Yöntemlerinin Uygulanması

\begin{tabular}{l} 
Matris Kalem Algoritmasının Uygulanması \\
\hline 1) $\quad$ Veri matrisi, sinyal kaynaklarından gelen sinyal tarafından üretilir. \\
2) $\quad \begin{array}{l}\text { uygulanmadan dizisine gelen sinyal gürültü içeriyorsa, Matris Kalem yöntemi } \\
\text { gürülü sinyaller için filtreleme işlevi görür. }\end{array}$ \\
3) Filtrelenmiş sinyal elde edilir. \\
4) Veri matrisi MP işlevine göre yeniden yapılandırılır. \\
5) Yeniden oluşturulan veri matrisinin öz değerleri hesaplanır. \\
6) Sinyal geliş açısı tahmini hesaplanır.
\end{tabular}

\section{Simülasyon Sonuçları}

$\mathrm{Bu}$ çalışmada, önerilen algoritma doğrusal anten dizisi kullanılarak birçok durum için analiz edilmiştir. Öncelikle sinyal kaynaklarının sayısı değiştirilerek geliş açısı tahmini yapılmıştır. Anten dizisine aynı frekans ve faza sahip üç uyumlu sinyal kaynağ $\left.185^{\circ}, 75^{\circ}, 60^{\circ}\right]^{\prime}$ lik farklı açılardan ışıma yaptığı varsayılmıştır. Bu sinyal kaynaklarına $45^{\circ}$ 'lik aynı faz ve frekansa sahip bir kaynak daha eklenmiştir. $N$ değeri $18, L$ değeri 6 ve anten dizisi elemanları arasındaki mesafe $\lambda / 2$ olarak alınmıştır. Tüm simülasyonlarda, anlık görüntü sayısı 1 adet alınmıştır. Her bir senaryoda $m=1000$ deneme yapılır, 1000 farklı tahmin sonucu bulunur ve bu 1000 farklı sonuç kullanılarak ortalama tahmin değeri hesaplanır. Anten dizisine aynı anda çarpan toplam 4 sinyal kaynağı olduğunda elde edilen sinyal geliş açısı tahmininin sonuçları Tablo 2'de gösterildiği gibidir. Performans değerlendirmesi, tahmini $\theta_{i}^{\prime}$ ve gerçek $\theta_{i}$ sinyal geliş açıları arasındaki ortalama karekök hatasına (RMSE) dayanmaktadır. RMSE = 
$\sum_{i=1}^{M} \sqrt{\left(\theta_{i}^{\prime}-\theta_{i}\right)^{2}} / m$ olarak hesaplanmıştır. Elde edile sonuçlara göre, sinyal kaynağı sayısı artsa da Matris Kalem yöntemi kaynakları birbirinden yüksek doğrulukla ayırt edebilmektedir.

Diğer simülasyonda, değişen sinyal kaynağı sayıları ile ortalama RMSE değerleri karşılaştırılmıştır. Sinyal kaynaklarının yine $\left[85^{\circ}, 75^{\circ}, 60^{\circ}, 45^{\circ}\right]^{\prime} l i k$ farklı açılardan 1şıma yaptığı varsayılmıştır. Simülasyon sonuçları, Şekil 1'de sunulmuştur. Sonuçlara göre sinyal kaynaklarının sayısı arttıkça RMSE ve yüzde hatası doğru orantılı olarak yükselir. Sonuçlar, Matris Kalem yönteminin artan sayıda sinyal kaynağı ile iyi sonuçlar verdiğini göstermiştir.

Tablo 2. Farklı sayıda sinyal kaynakları için geliş açısı tahminleri ve RMSE ile yüzde hata değerlendirmesi

\begin{tabular}{cccccc}
\hline $\begin{array}{c}\text { Sinyal } \\
\text { No }\end{array}$ & $\theta_{i}$ & $\begin{array}{c}\text { Sinyal } \\
\text { Kaynağ1 } \\
\text { Say1s1 }\end{array}$ & $\theta_{i}^{\prime}$ & $\begin{array}{c}\text { RMSE } \\
\left({ }^{\circ}\right)\end{array}$ & $\begin{array}{c}\text { Yüzde Hata } \\
(\%)\end{array}$ \\
\hline Sin.1 & 85 & & 84.9425 & 0.0575 & 0.0691 \\
Sin.2 & 75 & 3 & 75.0777 & 0.0777 & 0.1026 \\
Sin.3 & 60 & & 60.0245 & 0.0245 & 0.0408 \\
\hline Sin.1 & 85 & & 85.0456 & 0.0536 & 0.0911 \\
Sin.2 & 75 & 4 & 74.9029 & 0.1294 & 0.3129 \\
Sin.3 & 60 & 4 & 59.9601 & 0.0665 & 0.3830 \\
Sin.4 & 45 & & 44.9309 & 0.0691 & 0.1535 \\
\hline
\end{tabular}

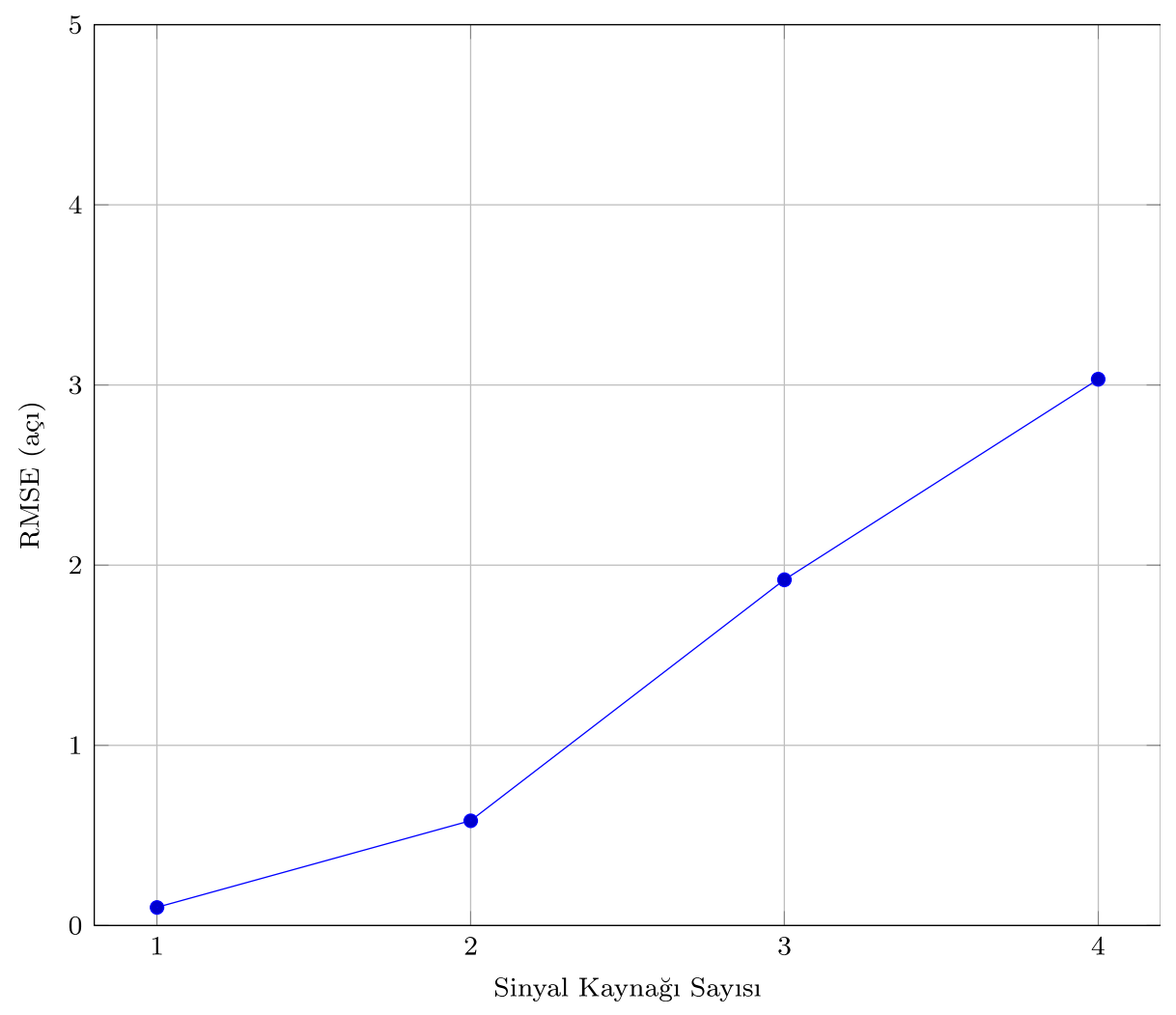

Şekil 1. Değișen sayıda sinyal kaynağı ile toplam ortalama RMSE, M=[1,2,3,4].

Şekil 2'de verilen simülasyonda, değişen sayıda anten $N=$ [10;36] ile 4 sinyal kaynağı analizinin sonuçları sunulmuştur. SNR değeri 30 dB'ye eşittir. Şekil 2'de anten elemanlarının sayısı arttıkça RMSE hatalarının azaldığı görülmektedir. Gelen sinyalin açısı tahmininin doğruluğu, N sayısı ile değişen L parametresinin seçiminden etkilenir. Simülasyon sonuçlarına dayanarak, 12'den fazla antenden oluşan bir doğrusal anten dizisi seçilmesi gerektiği anlaşılmıştır. Ayrıca önerilen yöntemin bir diğer sınırlaması, iletilen sinyallerin sayısının anten elemanlarının sayısının yarısını geçememesidir. Anten elemanlarının sayısı arttıkça Matris Kalem yönteminin performansı da artmaktadır. 
Diğer bir simülasyonda, Şekil 3, sinyal kaynakları $\mathrm{M}=[1 ; 4]$ çeşitli SNR seviyeleri ile sinyaller anten dizisine iletilir [0;35] dB. Burada N değeri 20 olarak alınmıştır. Sonuçlar, SNR seviyesi arttıkça gürültünün azaldığını ve hataların yaklaşık $10^{2}$ 'den $10^{-2}$ 'ye düştüğünü göstermiştir. Aynı SNR'nin gürültüsüne kıyasla sinyal kaynağı sayısı arttıkça RMSE değerinin de arttığı gözlenmiştir. Değişen SNR değerine rağmen Matris Kalem yönteminin 1 sinyal kaynağından 4 sinyal kaynağına kadar yüksek doğruluk değerleri elde ettiği görülmüştür.

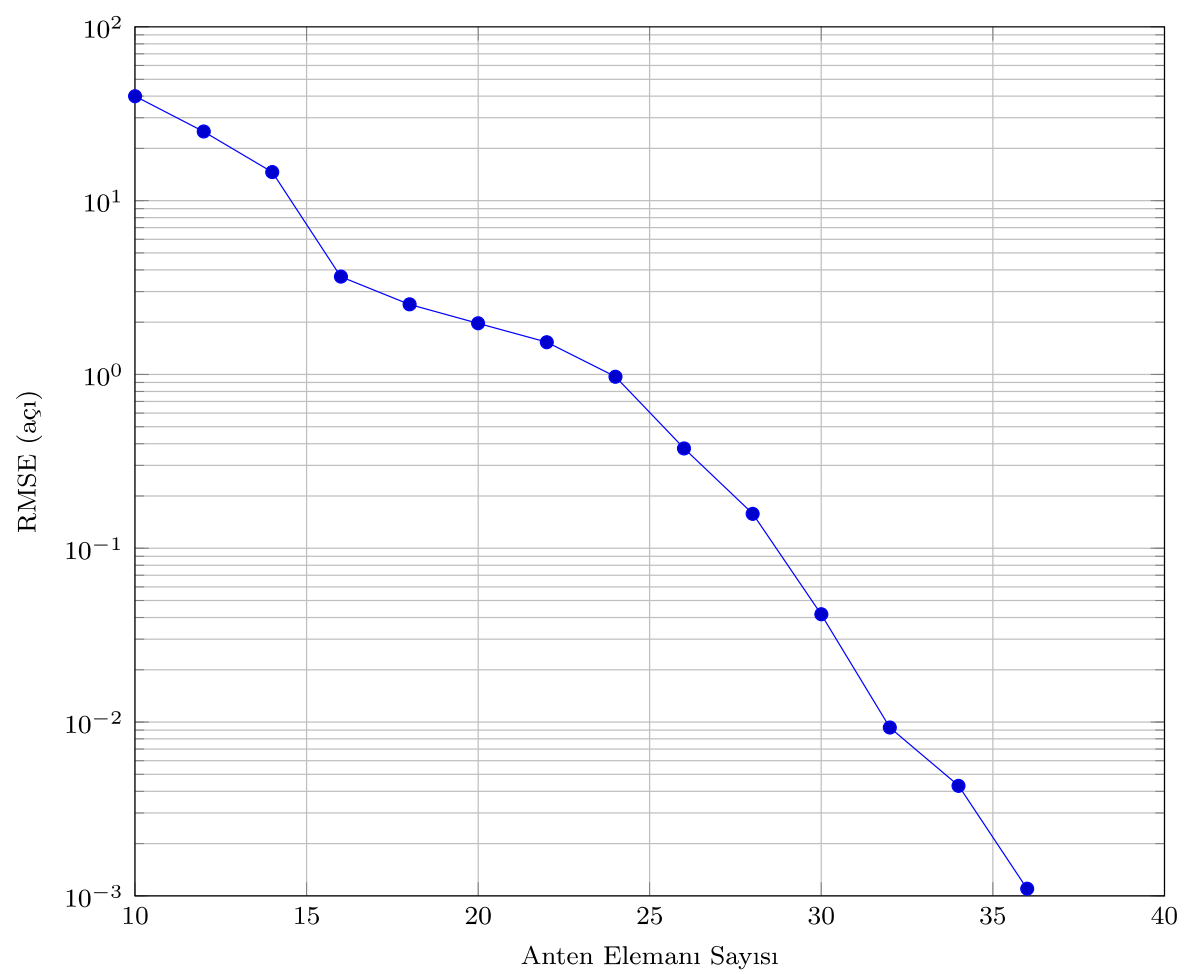

Şekil 2. Değişken sayıda anten elemanı ile RMSE N=[10,36].

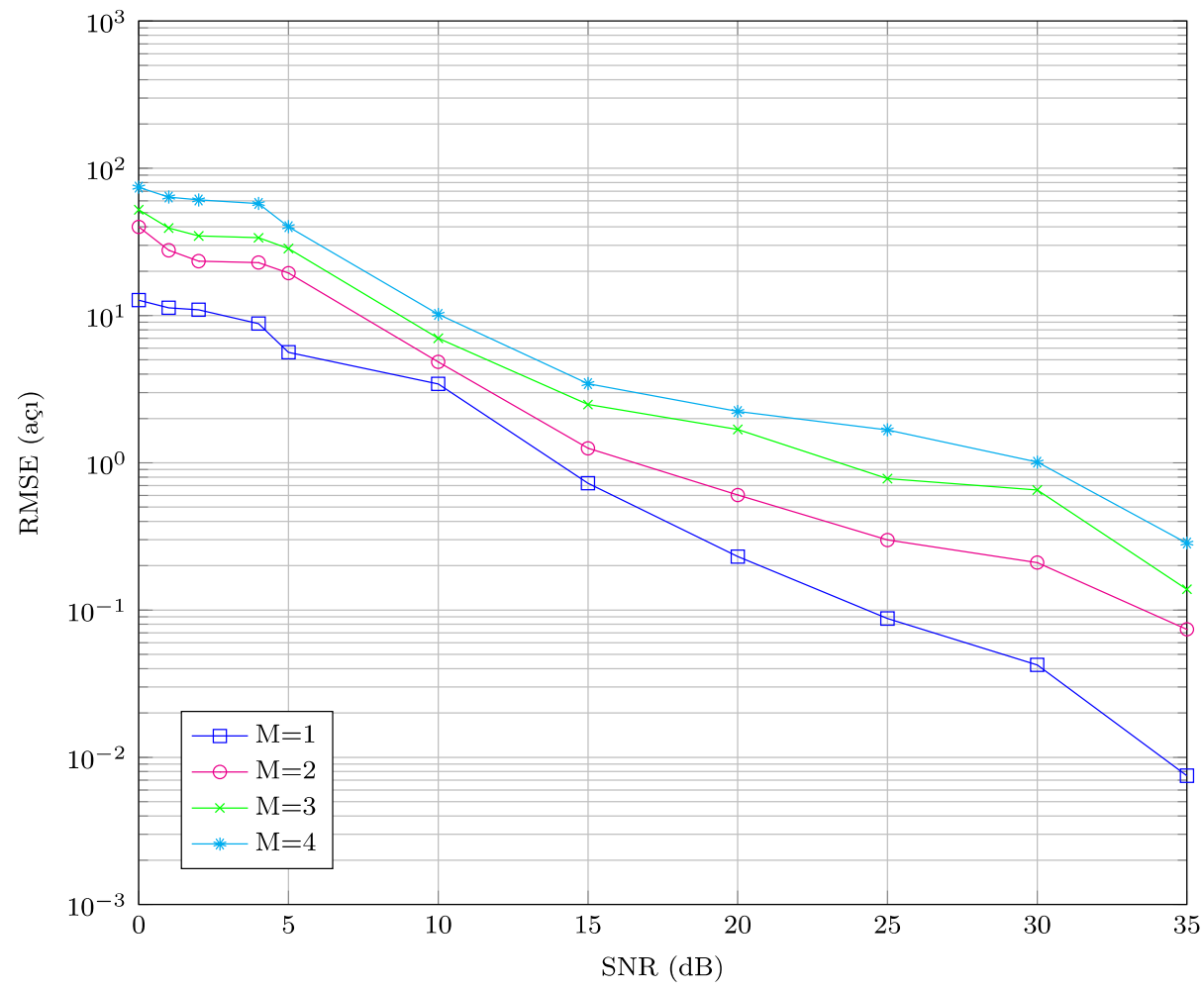

Şekil 3. Farklı sayıda kaynak için SNR ile geliş açısı tahmininin RMSE değerleri. 
Sinyal kaynağı sayısı 4 için elde edilen Tablo 3'de, sinyal geliş açısı tahmininde simülasyon sonuçları ESPRIT yöntemi ile karşılaştırılmıştır. Parametrik sinyal geliş açısı tahmini algoritmaları arasında ESPRIT, diğer parametrik algoritmalara kıyasla düşük hesaplama karmaşıklığı sunduğu için en yaygın kullanılanlardan biridir. Bu nedenle sonuçlar ESPRIT ile karşılaştırılmıştır. Bilindiği gibi ESPRIT yönteminde aynı frekans ve faz kaynakları kullanılarak açı tahmini yapılamaz. Bu nedenle 4 farklı frekans sinyal kaynağı kullanılmaktadır. Böylelikle Matris Kalem yönteminin farklı frekanslardaki performansı da analiz edilmiştir. N değeri 14 olarak alınmıştır. SNR değeri 35 dB'ye eşittir. Ayrıca anlık görüntü sayısı Matris Kalem yönteminde 1, ESPRIT algoritmasında ise 1024 olarak alınmıştır. ESPRIT tarafından tahmin edilen tüm durumlarda, Matris Kalem yöntemine kıyasla yüzde hatası daha yüksek elde edildiği görülmüştür. Tüm bunlar dikkate alındığında, Matris Kalem yönteminin farklı senaryolarda da az hata ile çalıştı̆̆ gözlemlenmiştir.

Tablo 3. ESPRIT ile Matris Kalem yönteminin 4 sinyal kaynağı için geliş açısı tahmininin yüzde hata karşılaştırması

\begin{tabular}{cccccc}
\hline $\begin{array}{c}\text { Sinyal } \\
\text { No }\end{array}$ & $\theta_{i}$ & $\begin{array}{c}\text { ESPRIT } \\
\left(\theta_{i}^{\prime}\right)\end{array}$ & $\begin{array}{c}\text { ESPRIT } \\
(\% \text { Hata })\end{array}$ & $\begin{array}{c}\text { Matris Kalem } \\
\left(\theta_{i}^{\prime}\right)\end{array}$ & $\begin{array}{c}\text { Matris Kalem } \\
(\% \text { Hata })\end{array}$ \\
\hline Sin.1 & 85 & 87.5784 & 3.033 & 84.9815 & 0.0217 \\
Sin.2 & 75 & 74.0612 & 1.2517 & 75.0155 & 0.2066 \\
Sin.3 & 60 & 59.7829 & 0.3618 & 60.0804 & 0.1340 \\
Sin.4 & 45 & 45.0044 & 0.0097 & 45.0021 & 0.0046 \\
\hline
\end{tabular}

\section{Sonuç ve Değerlendirme}

Bu makalede, ilk olarak 4 tane uyumlu ve daha sonra 4 tane uyumsuz sinyal kaynağı kullanarak doğrusal anten dizisi ile sinyalin geliş açısını tahmin etmek için Matris Kalem yöntemi ile Tekil Değer Ayrışımı yöntemini sunulmuştur. Bu alanda literatürde yapılan çalışmaların daha da geliştirilmesi adına, bu çalışmada, çok sayıda sinyal kaynağı ile Matris Kalem yöntemi ile geliş açısı tahmininin uygulaması incelenmiştir. Böylelikle önerilen algoritmanın 2'den fazla, 4'e kadar sinyal kaynağı sayısıyla iyi çalıştı̆̆1 kanıtlanmıştır. Önerilen algoritmaların performansları, sinyal kaynağı sayısı, anten elemanı sayısı, çeşitli SNR seviyeleri ve farklı frekanslar açısından analiz edilmiştir. Simülasyon sonuçları, Matris Kalem algoritmasının, çok düşük hatalarla birden çok sinyal kaynă̆ından gelen sinyalin açılarını tahmin edebildiğini göstermiştir. Ayrıca bu algoritma, 4 farklı açıdan gelen sinyallerin arasındaki açı farkı 10 derece kadar küçük olduğunda bile sinyalleri birbirinden ayırt edebilir. Böylelikle, yalnızca 1 anlık görüntü kullanılarak 4 taneye kadar sinyal kaynağının geliş yönlerinin tahmin edilebileceği gösterilmiştir.

\section{Referanslar}

[1] A. Paulraj, B. Ottersten, R. Roy, A. Swindlehurst, G. Xu, T. Kailath, "Subspace methods for directions-of-arrival estimation," Handbook of Statistics, Elsevier, vol. 10, pp. 693-739, 1993.

[2] G. Yong, X. Ci, Z. Zong, "Erasing false-location of two stations direction-finding cross location in multi-path and multiple sources environments," Radar, CIE International Conference on Proceedings, 2001.

[3] J. Capon, "High resolution frequency wave number spectrum analysis," Proc. 1EEE 57, pp. 1408-1418, 1969.

[4] J. P. Burg, "Maximum entropy spectral analysis,” Ph.D. thesis, Stanford University, Stanford, CA, 1975.

[5] V. F. Pisarenko, "The retrieval of harmonics from a covariance function," Geophys. J. Roy. Astronom. Soc. vol. 33, pp. 347-366, 1973.

[6] R. O. Schmidt, "Multiple emitter location and signal parameter estimation," Proc. RADC Spectrum Estimation Workshop. Griffiss AFB, NY, pp. 243-258, 1979.

[7] G. Bienvenu, L. Kopp, "Principle de la goniometrie passive adaptive,” Proc.7'eme Colloque GRESIT. Nice, France, pp.1$10,1979$.

[8] A. Paulraj, R. Roy and T. Kailath, "Estimation of signal parameters via rotational invariance techniques- ESPRIT," Proc. 19th Asilomar Conf. on Circuits, Systems and Computers. San Jose, CA, November, pp. 83-89, 1985.

[9] A. Paulraj, R. Roy and T. Kailath, “A subspace rotation approach to signal parameter estimation,” Proc. IEEE 74(7), pp. 1044-1045, 1986. 
[10] R. Roy, T. Kailath, “ESPRIT- Estimation of signal parameters via rotational invariance techniques,” IEEE Trans. Aeoust. Speech Signal Process. vol. 37(7), pp. 984-995, 1989.

[11] M. Viberg, B. Ottersten, T. Kailath, "Direction of arrival estimation and detection using weighted subspace fitting," Proc. 23rd Asilomar Conf. on Signals, Systems, and Computers, San Jose, CA, November, pp. 604-608, 1989.

[12] B. Ottersten, M. Viberg, T. Kailath, “Analysis of subspace fitting and ML techniques for parameter estimation from sensor array data,” IEEE Trans. Signal Process, vol. 40(3), pp. 590-600, 1992.

[13] L. Sibul, "Application of singular value decomposition to adaptive beamforming," Acoustics, Speech, and Signal Processing, IEEE International Conference on ICASSP, USA, 1984.

[14] Y. Hua, T.K. Sarkar, "Matrix Pencil method for estimating parameters of exponentially damped/undamped sinusoids in noise," IEEE Transactions Acoust. Speech, Signal Process. vol. 38 (1), pp. 814-824, 1990.

[15] T. K. Sarkar, O. Pereira, "Using the matrix pencil method to estimate the parameters of a sum of complex exponentials," IEEE Antennas and Propagation Magazine, vol. 37 (1), pp. 48-55, 1995.

[16] T. K. Sarkar, N. Yilmazer, M. Salazar-Palma, "DOA Estimation using Matrix Pencil and ESPRIT methods using single and multiple snapshots," Electromagnetic Theory (EMTS), URSI International Symposium, Berlin, Germany, 2010.

[17] B. Hiçdurmaz, F. Durak, S. Özyön, "The Estimation of Bessel Type Low-Pass Active Filter Parameters with Charged System Search Algorithm” International Scientific and Vocational Studies Journal, pp. 65-67, 2019.

[18] M. Ihedrane, S. Bri, A. E. Fadl, "2-D Matrix pencil for doa estimation," International Conference on Wireless Technologies, Embedded and Intelligent Systems (WITS), 2019.

[19] N. Aytaş, E. Afacan, N. İnanç, “The Application of Matrix Pencil Method for Direction Finding Using a Linear Antenna Array," 29th Signal Processing and Communications Applications Conference (SIU), pp. 1-4, 2021. 